\title{
SANAYİ KAYNAKLI KARBONMONOKSIT SALINIMLARININ AERMOD DAĞILIM MODELİ İLE İNCELENMESİ
}

Öz: Bu çalışma, özellikle kış mevsimlerinde yoğun hava kirliliğinin yaşandığı Balıkesir ili için yapılmış ilk hava kalitesi modelleme çalışmasıdır. Balıkesir il merkezinde bulunan bir sanayi işletmesinden atmosferik karbonmonoksit (CO) salınımlarının kent merkezine olan olası etkileri mevcut meteorolojik ve yüzey topoğrafya özellikleri dikkate alınarak incelenmiş ve $\mathrm{CO}$ salınımlarına ait yeryüzü konsantrasyonlarının dağılımlarını gösteren haritalar AERMOD ile oluşturulmuştur.

Elde edilen sonuçlara göre, Balıkesir ili için uzun yıllık hakim rüzgar yönü Kuzey (N) ve Kuzey-Doğu (NE) yönlü olarak belirlenmiştir ve kaynaktan yayılan maksimum günlük 8 saatlik ortalama $\mathrm{CO}$ konsantrasyonu modelleme sonucuna göre $34,01 \mu \mathrm{g} \cdot \mathrm{m}^{-3}$ olarak tahmin edilmektedir. Bu nedenle, tahmin edilen CO seviyelerinin yasal sınırları aşmadığı ve șehir merkezine olumsuz bir etkisinin olmadığı belirlenmiştir. Ayrıca incelenen kaynağa yakın kabul edilebilecek yerde tam teşekküllü bir hastanenin olması, yapılan çalışmayı daha önemli bir hale getirmektedir. Modelleme sonucuna göre, kaynaktan salınan maksimum günlük 8 saatlik ortalama $\mathrm{CO}$ konsantrasyonu yaklaşık $10 \mu \mathrm{g} \cdot \mathrm{m}^{-3}$ olarak tahmin edilmiş olup, bu değerin yine aynı yönetmelikte izin verilen yasal sınırları aşmadığı tespit edilmiştir. Çalışma sonuçlarının, halkın bilinçlendirilmesine katkı sağlanması ve yerel otoriteye karar alma sürecinde öneriler sunulması da ayrıca çalışma kapsamında önem arz etmektedir.

Anahtar Kelimeler: CO, Balıkesir, Hava kalitesi, AERMOD, AERMET

An Investigation of Industrial Carbon monoxide Depositions Using AERMOD Dispersion Model

Abstract: This study is the first air quality modeling study for downtown Balikesir where intense air pollution levels are experienced during the winter seasons. The possible effects of atmospheric carbonmonoxide (CO) emissions from an industrial operation in downtown Balikesir were examined by taking into consideration the existing meteorological and surface topography characteristics and the maps showing the distributions of the ground level concentrations for $\mathrm{CO}$ releases were created by using the AERMOD.According to the results, the prevailing wind direction was determined as North $(\mathrm{N})$ and North-East (NE) for Balikesir province, and the maximum daily 8-hour means of $\mathrm{CO}$ concentration emitted from the source was estimated as $34,01 \mu \mathrm{g} \cdot \mathrm{m}^{-3}$ for the modeling study. For this reason, it has been determined that the modeled $\mathrm{CO}$ concentrations do not exceed the legal limits and there is no adverse effect on the downtown area. In addition, the fact that, there was a full-scaled hospital that was located nearby the source. The location of hospital complex made the air quality modeling study more significant. According to the modeling result, the maximum daily 8-hour means of $\mathrm{CO}$ concentration released from the source was estimated to be about $10 \mu \mathrm{g} . \mathrm{m}^{-3}$ for the hospital area. It has also been determined that the modeled value for hospital does not exceed the legal limits as states in the regulation. Within the scope of the study, the obtained results are also important due to contribution to raising public awareness and also provide suggestions to local authority in decision-making process.

Keywords: CO, Balikesir, Air quality, AERMOD, AERMET

\footnotetext{
* Dr.Öğr.Üye.Atilla MUTLU Balıkesir Üniversitesi, Çevre Mühendisliği Bölümü, 10145 Çağış Yerleşkesi-Balıkesir İletişimYazarı: Atilla MUTLU (amutlu@balikesir.edu.tr)
} 


\section{GİRIŞ}

Her geçen gün artan hava kirliliği günümüzde ve gelecekte canlı yașamını ve bu nedenle ekolojik dengeyi olumsuz yönde etkilediği artık bilinen bir gerçektir. Gelişmiş veya gelişmekte olan toplumlarda var olan sürekli artan nüfus ile birlikte gelen, düzensiz şehirleşme, kontrolsüz sanayileşme ve her geçen gün artan enerji ihtiyacı yaşadığımız ortamdaki temiz hava kalitesini azaltarak sadece bizleri değil aynı zamanda yaşadığımız doğal hayatı da tehdit etmektedir (Gokhale ve Khare, 2005).

Hava kirliliği ile mücadele, insanlığın çevreye dolayısıyla atmosfere olan olumsuz etkilerinin azaltılmasına veya en azından kontrol edilmesine karşı yapılmakta olan teknik (mühendislik) ve sosyal (eğitim) içerikli mücadelenin canlı bir örneğidir. Bu mücadelede dikkat çeken bazı kontrolsüz tekrarlanan zararlı, toksik maddelerin atmosfere salınımları, geçmişteki dönemlerde karşımıza 'Episod' denilen kirlilik faciaları olarak adlandırılan trajik olaylara yol açmıştır. Bu trajidelerden bazıları; Bhopal gaz faciası, Meksika'daki Mexico City olayı; 1953, 1963 ve 1966 yıllarında yaşanan New York kenti episodları ve 1950'li ve 1960'lı yıllarda yaşanan Meuse Valley ve Londra şehrini mahfeden duman episodları örnek verilebilir (Wang ve ark., 2004; Visscher, 2014)

Özellikle nüfusun yoğun olduğu şehirlerde, hava kalitesinin artırılabilmesi için öncelikle kirletici parametrelerin türü, miktarı ve kirletme süresi belirlenmelidir. Bir başka ifadeyle, bölgenin emisyon envanteri oluşturulmalıdır. Son yıllarda, hava kalitesinin artırılması için uygulanacak stratejinin belirlenmesi o bölgeye ait hava modelleme tekniklerinin de uygulanması önem arz etmektedir.

Küresel ölçekde, başlıca antropojenik hava kirleticiler kent merkezlerinde yoğunlaşmıştır. Trafik, endüstri ve 1sınma sistemleri kentsel hava kirliliğinin başlıca kaynaklarıdır. Meteoroloji, yeryüzü şekilleri ve kent yerleşimleri hava kirleticilerinin dispersiyon, depolanma ve kimyasal dönüşüm süreçlerine etki eden önemli faktörlerdir. Çeşitli hava kirleticilerinin çevreye ve insan sağlığına olumsuz etkileri bilinmektedir. Her bir hava kirleticinin etki süresi, konsantrasyonu ve diğer karakteristiklerine bağlı olarak insan sağlığı üzerinde etkileri olmaktadır. İnsanlar üzerindeki klinik çalışmalarda ozon $\left(\mathrm{O}_{3}\right)$, kükürtdioksit $\left(\mathrm{SO}_{2}\right)$, partiküler madde $(\mathrm{PM})$, azot oksitler $\left(\mathrm{NO}_{\mathrm{x}}\right)$ ve karbonmonoksit $(\mathrm{CO})$ gibi başlıca kirleticilerin başta solunum yolu olmak üzere, kalp, rahatsızlığını arttırdığı rapor edilmiştir (Helander ve ark., 1997; Monn ve ark., 1999; Moshammer ve Neuberger, 2003; Martonen ve Schroeter, 2003; Vallero, 2008; Borge ve ark., 2014). Pek çok epidemiolojik çalışmada özellikle astım gibi kronik solunum yolu hastalığına çevresel hava kirliliğinin olumsuz ektisi olduğu kabul edilmektedir (Alberini ve Krupnick, 1998; Williams ve ark., 2000; Tecer, 2009).

Benzer çalışmalar, hava kirliliği seviyesi ile akciğer fonksiyonlarında düşüş, solunum yolu semptomlarında artış ve ölüm vakalarında artış arasında bir ilişkinin olduğunu göstermektedir (Wordley ve ark., 1997; Timonen ve ark., 2002). Yetişkin ve çocuklarda, solunum yolu şikayetleri veya astımda şiddetlenme sebebiyle hastaneye yatışlarda ve acil servislere başvurulardaki artışla hava kirliliği arasında ilişki olduğu ifade edilmiştir (Gomzi, 1999; Wong ve ark., 2000; Brunekreef. ve Holgate, 2002).

Başlıca zararlı hava kirleticilerinden olan karbonmonoksit, hemen hemen her yanma işlemi sonucunda ortaya çıkan renksiz, kokusuz ve toksik özelliği olan bir gazdır. Fazla miktarda ve kısa zamanda, yani akut etki durumunda, vücuda solunum yoluyla alındığında, insan vücudunda baş dönmesi, bilinç kaybı ve hatta ölüm gibi son derece tehlikeli durumlara neden olabilir. Atmosferik karbonmonoksit salınımlarına maruz kalındığında, özellikle kalp rahatsılığı bulunan kişiler için de, önemli sağlık riski teşkil etmektedir (USEPA, 2018). Kalp rahatsızlı̆̆ olan kişilerde vücutlarında yaşamsal faaliyetleri için gerekli kan dolaşımı ile oksijen taşınabilme özelliği zaten kısıtlı olduğundan, akut etki olarak bu kirletici gaza maruz kalındığında, akciğer alveollerinde oksijen taşıyan oksi-hemoglobin yerine hemoglobinlerin oksijenden yaklaşık 200 kat daha hızlı bir şekide $\mathrm{CO}$ absorbe etmesiyle oluşan carboksi-hemoglobinlerin kanda 
taşınmasıyla yaşamsal faaliyetler açısından önem arz eden kalp, beyin gibi organlara yeterince oksijen iletilememesinden dolayı çok ciddi sağlık riskleri oluşmaktadır (Vallero, 2008). Karbonmonoksit çevremizde taşıtlar, iş makinaları ve ayrıca fosil yakıt yakılan hemen hemen bütün kaynaklardan atmosphere salınmaktadır (USEPA, 2018).

Son yıllarda dünyada yaygın olarak kullanılmakla birlikte ülkemizde kullanımının son dönemlerde artı̧̧ gösterdiği AERMOD (The American Meteorological Society/Environmental Protection Agency Regulatory Model) gibi hava kirliliği dağılım modellerinin uygulanması, özellikle kış mevsiminde yoğun hava kirliliğinin yaşandığı Balıkesir ili için bu kapsamda yapılmış ilk çalışma olması bakımından önem arz etmektedir.

$\mathrm{Bu}$ nedenle, Balıkesir il merkezinde bulunan bir sanayi işletmesinde atmosfere verilen $\mathrm{CO}$ salınımlarının kent merkezine olan olası etkileri mevcut meteorolojik ve yer yüzü şekilleri dikkate alınarak incelenmiştir. Elde edilen sonuçların, bölge halkın bilinçlendirilmesine katkı sağlanması ve yerel otoriteye karar alma sürecinde öneriler sunması da ayrıca çalışma kapsamında amaç edilmiştir.

\section{MATERYAL ve YÖNTEM}

\section{1. Çalışmanın Yapıldığı Yer}

Balıkesir ili şehir merkezine ait hava kalitesinin incelendiği bu çalışmada, şehir merkezine en yakın olan işletmelerden bir tanesi seçilmiştir. Balıkesir şehir merkezine yakın konumda bacası olan sanayi işletmeleri nispeten şehrin güney-batı bölgesinde kurulmuş olan Organize Sanayi Bölgesinde faaliyet göstermektedir. Şehir merkezine ait hava kalitesine etkisinin incelendiği çalışmaya konu olan işletmenin konumu (kaynak) Şekil 1'de gösterilmiştir.

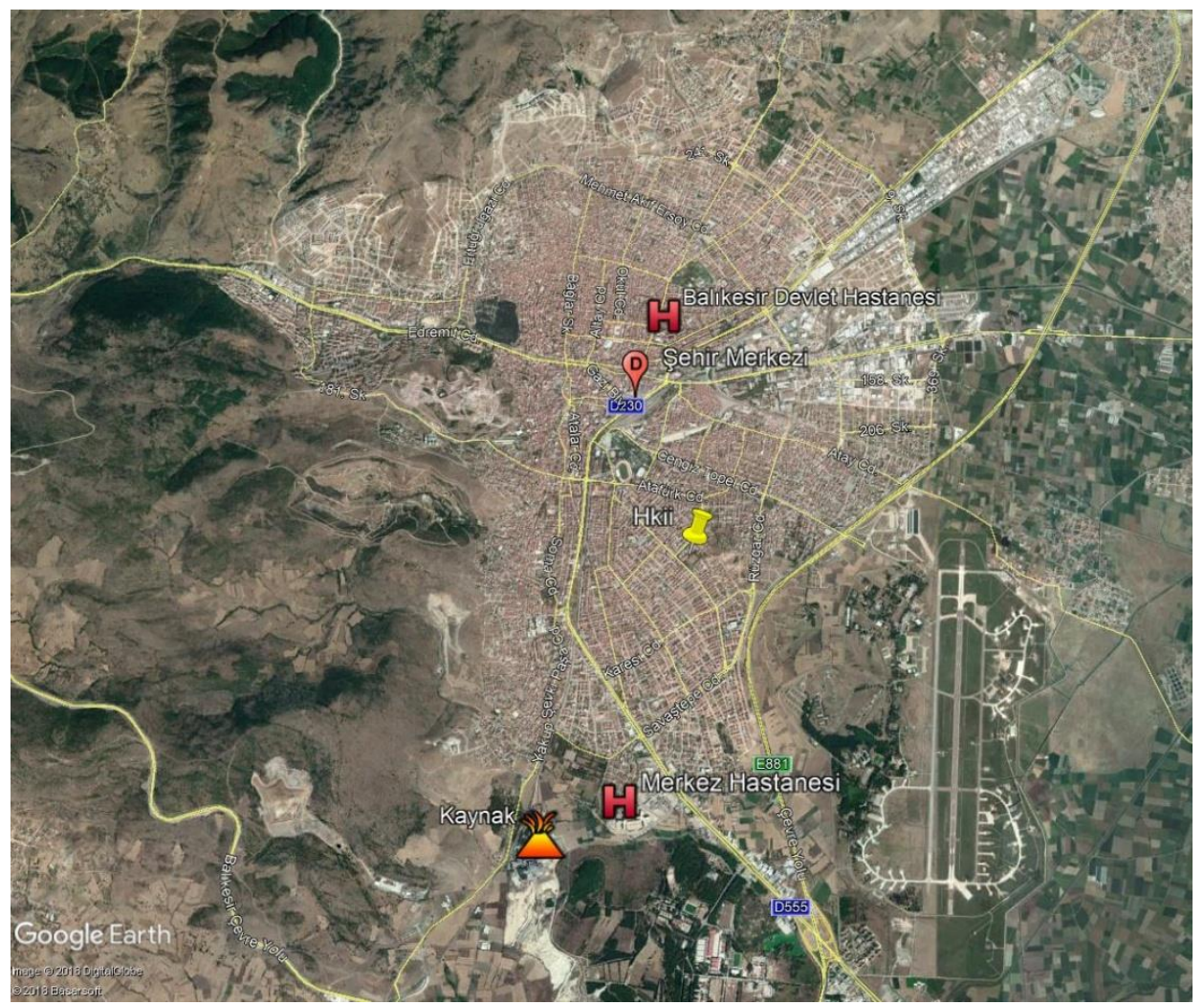

Şekil 1:

Hava kalitesi modellemesi için incelenen işletme yeri 
Çalışmanın yapıldığı işletme çimento üretimi yapan bir tesis olup, işletme bacasına ait fiziksel ve ölçülmüş olan parametreler Balıkesir ili için yapılmakta olan "Temiz Hava Eylem Planı” kapsamında İl Çevre Müdürlüğü tarafından temin edilmiştir.

Tablo 1. Çalışmanın yapııldığı kaynağa ait başlıca parametreler

\begin{tabular}{|l|l|l|l|}
\hline \multicolumn{2}{|c|}{ Fiziksel Parametreler } & \multicolumn{2}{c|}{ Ölçülen Parametreler } \\
\hline Kaynak Tip & Farin Fırın Torbalı Filtre & Baca sıcaklığ $1,{ }^{\circ} \mathrm{C}$ & 97,6 \\
& Bacası & Yanma verimi, \% & 81,2 \\
Is1l gü̈c, MW & 96 & Nem, \% & 9,5 \\
Yakı̈t türü & İthal kömür/petrokok & Basıç, mmHg & 767,49 \\
Baca çap1., m & 3,33 & Baca gazı hızı, m.s ${ }^{-1}$ & 14,6 \\
Baca yüksekliği, m & 78 & Baca gazı debisi, $\mathrm{m}^{3} . \mathrm{sa}^{-1}$ & 307470,97 \\
\hline
\end{tabular}

İșletme bacasına ait teknik özellikler Tablo 1'de verilmiș olup, söz konusu incelenen bacadan salınan CO kütlesel debi ortalama olarak 46,98 kg.sa ${ }^{-1}$ olarak ölçülmüştür. Kütlesel debi miktarı ilgili mevzuatta (SKHKKY-EK1, 2014) belirtilen sınır değerini (500 kg.sa ${ }^{-1}$ ) aşmadığı tespit edilmiştir. Baca gazı çıkış hızı, bu işletme için 14,6 m.s ${ }^{-1}$ ölçülmüş olup, bu parametre yine aynı yönetmelikte ifade edildiği gibi, 1sıl gücü 500kW'ın üzerinde olan işletmeler için, gazların bacadan çıkış hızları en az $4 \mathrm{~m} \cdot \mathrm{s}^{-1}$ olmalıdır ifadesine bağlı olarak yasal sınır değerin üstünde olduğu tespit edilmiştir. Tablo 1'de verilen parametreler AERMOD içinde işletmeye (kaynak) ait veriler (input) olarak modelleme çalışmasında kullanılmıştır.

\section{2. Çalışma Planı ve Veri Analizleri}

Modelleme çalışmasında gereksinim duyulan, söz konusu işletmeye ait, CO emisyon değerleri ve işletmeye ait bacanın fiziksel özellikleri Balıkesir Valiliği tarafından yürütülmekte olan "Balıkesir İli Temiz Hava Eylem Planı" kapsamında İl Çevre Müdürlüğü’nden alınmıştır. Yine "Temiz Hava Eylem Planı" çalışması kapsamında, hava kalitesi modellemesinin yapılabilmesi için gerekli olan meteorolojik veriler (saatlik olarak rüzgar hızı, rüzgar esme yönü ve sayısı ve sıcaklık, yağış, basınç, bulutluluk) ise Meteoroloji İl Bölge Müdürlüğü'nden temin edilmiştir.

Sunulan çalışmada, modelleme uygulaması için kaynaktan yapılan salınımlar kadar o bölge için etkili olan karakteristik meteorolojik ve yüzey verilerinin tam olarak elde edilerek gerekli veri tabanlarının oluşturulması önem arz etmektedir.

Çalışma bölgesine ait, karakteristik meteorolojik verilerden ilk aşamada, modelleme işlemi için gerekli olan "temsili yıl" tanımı yapılmıştır. Bu tanımlama için, son beş yıla ait rüzgar verileri kullanılmıştır. Temsili yılın seçilmesinde, uzun yıllık rüzgar veri seti geçmişe dönük daha uzun bir periyoda sahip olması her ne kadar arzu edilen bir durum olsa da, ilgili kuruluşlardan imkanlar dahilinde elde edilen periyod beş yıl olarak (2012-2016 yılları arası) analiz edilmiştir.

Son beş yıla ait rüzgar verisi incelendiğinde rüzgar yönü ve esme sayısı bakımından "temsili yıl" 2016 yılı olarak belirlenmiştir. Bu nedenle çalışmamızda, 2016 yılına ait saatlik rüzgar verileri, sıcaklık, basınç, yağış, bulutluluk, karışım yüksekliği gibi meteorolojik değerler kullanılmıştır. Şekil 2'de 2012-2016 y1llarına ait beş yıllık rüzgar verileri ve en son grafikte bölgeyi temsil eden hakim rüzgar yönünü gösteren dağılım R ortamında, OpenAir algoritması kullanılarak sunulmuştur (Carslaw, D.C. ve K. Ropkins, 2012; Carslaw, D.C., 2015). 

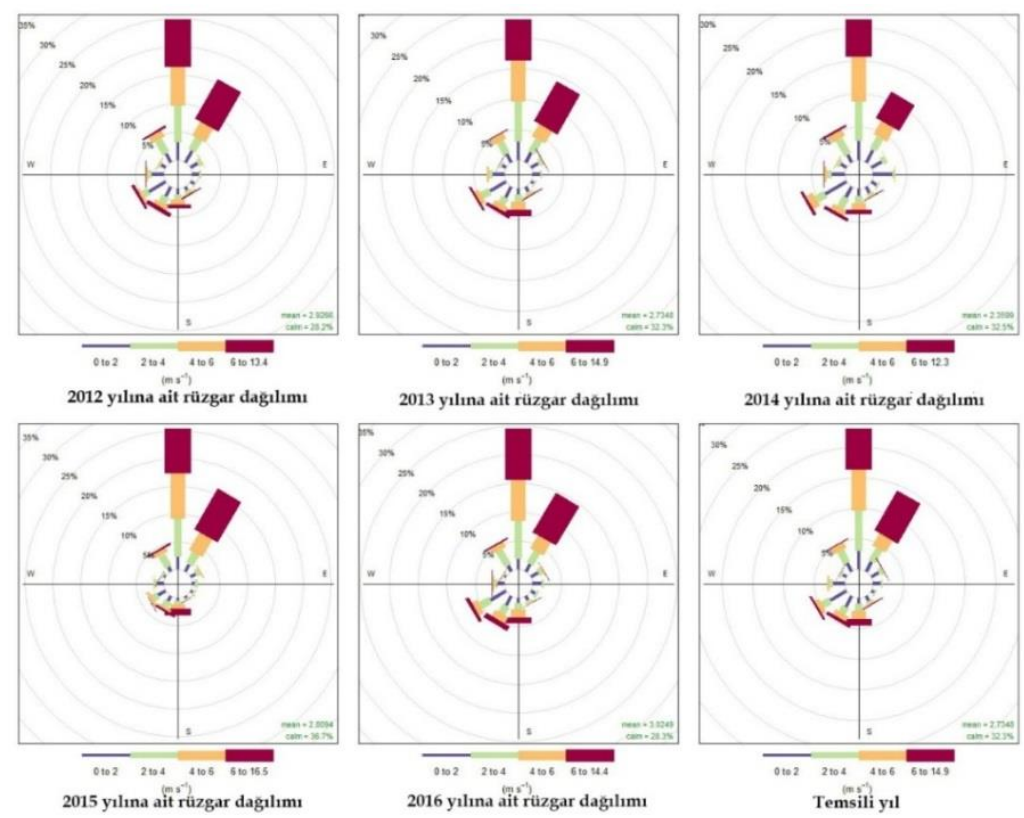

Şekil 2:

Bölgeye ait son beş ylla ait rüzgar dağllımları ve temsili hakim rüzgar yönü
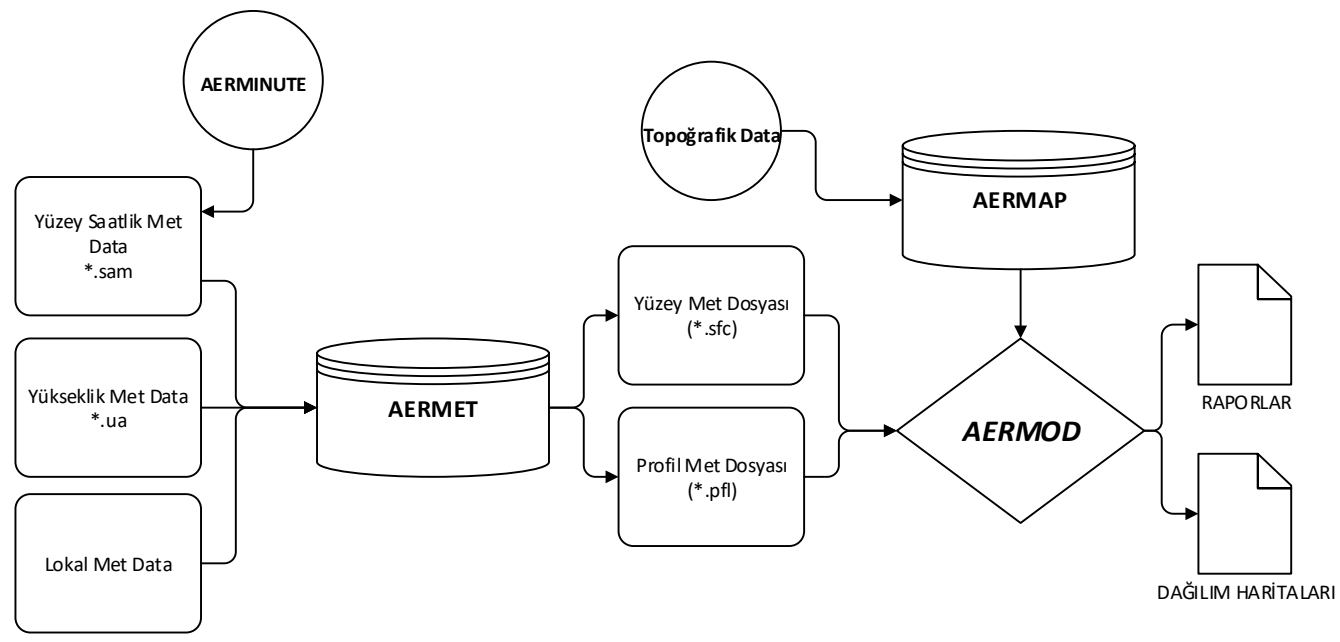

Şekil 3:

Hava kalitesi dă̆̆lım modeli için izlenen adımlar

Çalışma bölgesine ait, temsili yıl ve hakim rüzgar yönü belirlendikten sonra seçilen temsili yıla ait meteorolojik yüzey ve yükseklik verileri en yakın meteorolojik istasyonlardan elde edilip, modelleme programında kullanılmak üzere uygun veri tabanı haline getirilmiştir. Modelin çalışmasına ait akım şeması Şekil 3'de gösterilmiştir.

Şekil 3'de görüldügü gibi temsili yıla ait tüm meteorolojik veriler, kapsamlı olarak düzenlenip, Surface (yüzey) ve Upper (ravinsonde) meteoroloji verileri olarak ayr1 2 veri taban1 halinde hazırlanmıştır. Hazırlanan iki ayrı meteorolojik veri tabanı daha sonra AERMET adı verilen meterojik veri analizi işlemcisine aktarılmaktadır. Dağılım modelinin sorunsuz olarak çalışabilmesi için AERMET'e aktarılan veri tabanında hiçbir şekilde tanımlanan format dışında bir veri yapısının olmaması gerekmektedir. AERMET işlemcisi, iki ayrı meteorolojik veri tabanı 
modellemede uygun olarak kullanılmak üzere *.sfc ve *.pfl uzantılı dosyalar haline dönüştürerek, AERMOD işlemcisine göndermektedir.

AERMET tarafından hazırlanan meteorolojik veri tabanlarını oluşturan dosyalar ve AERMAP tarafından hazırlanan, modelleme çalışmasının yapılacağı bölgeye ait yükselti ve karakteristik yüzey verilerini içeren dosyalar daha sonra AERMOD ana işlemcisi tarafindan farklı katmanlar (layers) olarak alınmaktadır . Son olarak, kirletici salınımı yapan kaynağa ait veriler de ayrı bir katman olarak ilave edilerek hava kalitesi dağılım haritaları çalışma bölgesi için oluşturulmaktadır.

\section{BULGULAR}

Analiz sonucunda, kaynaktan atmosfere salınan CO kirleticisine ait modellenen yeryüzü konsantrasyon değerleri; 8 saatlik, günlük ve yıllık olmak üzere üç farklı zaman dilimi için maksimum ortalama değerleri olarak ifade edilmektedir. İlgili yönetmelik gereğince (HKDYY, 2008), CO salınımları için maksimum günlük 8 saatlik ortalama konsantrasyon değerleri kullanılması gerekmektedir. Yönetmelikte adı geçen maksimum günlük sekiz saatlik ortalama konsantrasyon değeri, hesaplanan saatlik verilerden oluşur ve her saat güncellenen sekiz saatlik dinamik ortalamalar şeklinde ifade edilir (HKDYY, 2008).

Modelleme sonucunda (outputs), insan sağlığının korunması için ilgili yönetmelikte belirtildiği üzere, maksimum günlük 8 saatlik ortalamalar baz alınarak alıcı noktaya (receptor) gelen en yüksek yeryüzü CO konsantrasyonu değerleri rapor edilir.

Model ekstrem koşullar altında çalıştırılmış olup belirli zaman dilimlerine göre tahmin edilen yeryüzü $\mathrm{CO}$ seviyelerine ait ortalamaların en yüksek değerleri sunulmuştur. Çalışma bölgesine ait kaynaktan yayılan maksimum günlük 8 saatlik ortalama yeryüzü $\mathrm{CO}$ konsantrasyonu, Şekil 4'de sunulan modelleme sonucuna göre $34,01 \mu \mathrm{g} . \mathrm{m}^{-3}$ olarak 29.Şubat.2016 tarihinde gece yarısında oluştuğu tahmin edilmektedir.

Balıkesir ilinde halen aktif olarak ölçüm yapan bir adet hava kalitesi ölçüm istasyonu bulunmaktadır. Bu istasyonda, 2018 yılından itibaren düzenli olarak dış ortam $\mathrm{CO}$ ölçümleri yapılmaktadır. Ölçüm sonuçlarına göre, 8 saatlik ortalama dış ortam CO konsantrasyonu 1954 $\mu \mathrm{g} . \mathrm{m}^{-3}$ olarak rapor edilmiştir (Hava Kalitesi İzleme, 2018). Modelleme sonuçları ile Balıkesir iline ait ölçülmüş olan dış ortam CO seviyeleri arasındaki farkın oldukça yüksek olduğu tespit edilmiştir. İl merkezinde ölçülen dış ortam CO farkının nedeni, modellemede kullanılan işletmenin salt etkisinden çok şehir merkezindeki 1sınma ve ulaşım kaynaklı faaliyetlerin etkili olduğu düşünülmektedir.

Aynı zaman dilimlerine ait dış ortam ortalama CO seviyeleri Çanakkale ilinde $333 \mu \mathrm{g} . \mathrm{m}^{-3}$, İzmir-Bornova'da $812 \mu \mathrm{g} \cdot \mathrm{m}^{-3}$, İstanbul-Aksaray'da $667 \mu \mathrm{g} \cdot \mathrm{m}^{-3}$ ve Kocaeli-Dilovası'nda ise $614812 \mu \mathrm{g} \cdot \mathrm{m}^{-3}$ olarak ölçülmüştür. Balıkesir il merkezinde ölçülen ortalama CO seviyeleri $\left(1954 \mu \mathrm{g} \cdot \mathrm{m}^{-3}\right)$ diğer bölgelerde bulunan illerdeki CO seviyeleri ile klyaslandığında nispeten daha yüksek olduğu anlaşılmaktadır. Diğer ülkelerde yapılan benzer çalışmalarda rapor edilen dış ortam CO seviyeleri ile kıyaslandığında oldukça benzer seviyede olduğu görülmektedir. Şöyleki, Aneja ve ark. (2001) yılında yapılan çalışmada, Hindistan'ın New Delhi metropol şehri için yapılan atmosferik CO ölçümlerinde şehir merkezi için $1939 \mu \mathrm{g} \cdot \mathrm{m}^{-3}$ değeri rapor edilmiş olup, aynı çalışmada atmosferik CO seviyelerinin A.B.D. için 200-500 $\mu \mathrm{g} \cdot \mathrm{m}^{-3}$ arasında olduğu belirtilmiştir. Çin'de 272 şehirde yapılan başka bir çalışmada ise yıllık CO ortalamasının yaklaşık $1200 \mu \mathrm{g} \cdot \mathrm{m}^{-3}$ olduğu rapor edilmiş olup ayrıca ortalama CO seviyesinin $1000 \mu \mathrm{g} \cdot \mathrm{m}^{-3}$ artması durumunda CO kaynaklı ölümlerde yaklaşık \%1,12 lik bir artışın olabileceği belirtilmiştir (Liu ve ark., 2018). 


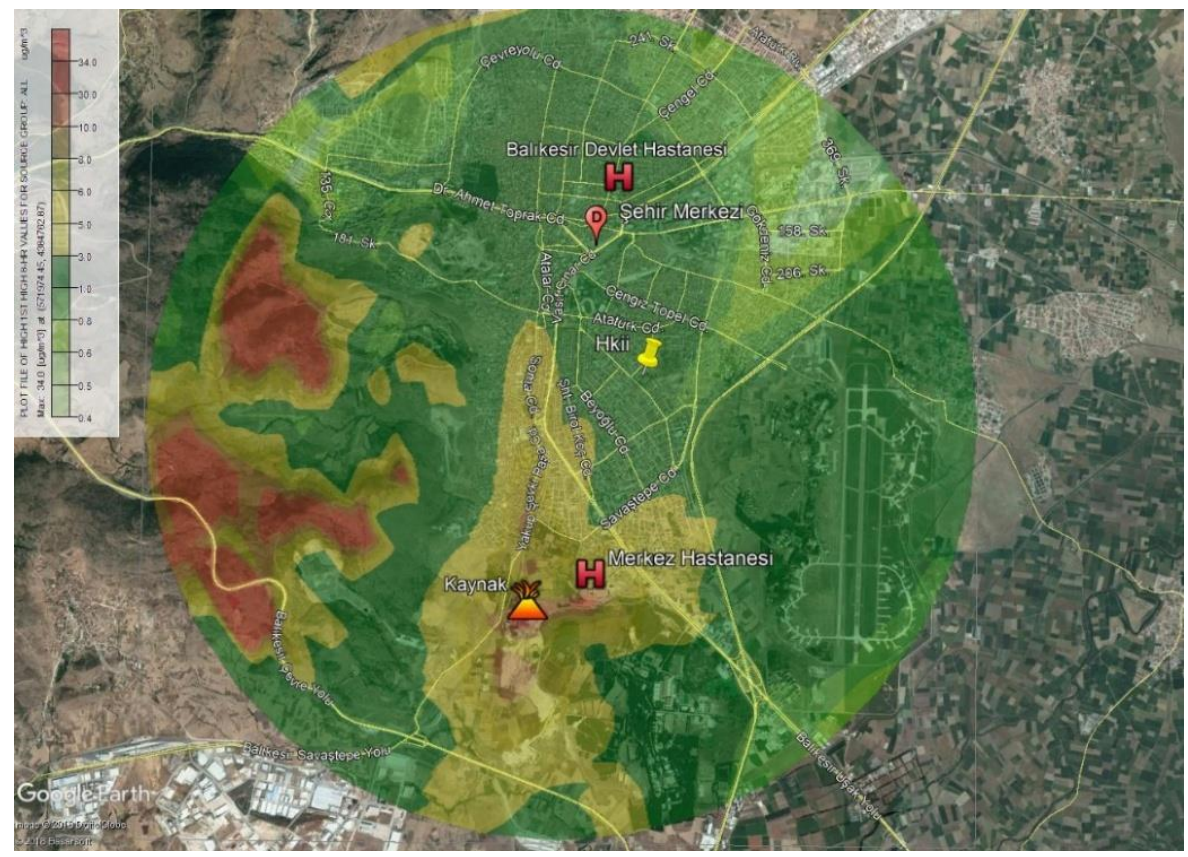

Şekil 4:

Kaynak etkisinde il merkezinde oluşan maksimum günlük 8 saatlik ortalama CO dağılımı

Çalışma bölgesine ait kaynaktan yayılan CO yeryüzü konsantrasyonları zaman içinde rüzgar yönünün değişmesiyle birlikte mekânsal olarak sürekli değişim göstermektedir. Hava Kalitesi Değerlendirme ve Yönetimi Yönetmeliği Ek-1 A'da belirtildiği gibi, CO konsantrasyon limit değerlerinin azaltılması için 2014 yılından itibaren bir geçiş süreci oluşturulmuş ve Kısa Vadeli Sınır (KVS) ve Uzun Vadeli Sınır (UVS) kademeli olarak azaltılmıştır. Hedeflenen tarih olan 1.Ocak.2017 tarihi itibariyle maksimum günlük 8 saatlik ortalama ve yıllık limit değerler $10 \mathrm{mg} \cdot \mathrm{m}^{-3}$ (Bir başka ifadeyle $10000 \mu \mathrm{g} \cdot \mathrm{m}^{-3}$ ) olarak sınırlandırılmıştır (HKDYY, 2008).

Tahmin edilen maksimum günlük 8 saatlik ortalama $\mathrm{CO}$ salınımı şehrin daha çok Batı kısmında etkili olduğu görülmüştür (Şekil 4). Kaynaktan salınan, modellenmiş yeryüzü CO konsantrasyonlarının şehir merkezinde yaklaşık $3 \mu \mathrm{g} \cdot \mathrm{m}^{-3}$ seviyelerinde ve rüzgar yönüne göre işletmenin rüzgar üstü (upwind) bölgesinde yani arka plan olarak nitelendirilen bölgesinde olduğu yine Şekil 4.'de görülmektedir. Ayrıca, modellenmiş yeryüzü CO seviyelerinin yönetmelik sınır değerlerini aşmadığı tespit edilmiş olup, şehir merkezi için bir risk teşkil etmediği anlaşılmıştır.

Modelleme sonucunda elde edilen yıllık tahmini yeryüzü CO seviyeleri ise yine aynı temsil yılına göre en kötü şartlarda ve maksimum yeryüzü CO konsantrasyon ortalaması baz alınarak yapılmıştır. Çalışma bölgesine ait kaynaktan yayılan maksimum ortalama yıllık yeryüzü CO modelleme sonuçları Şekil 5'de sunulmuştur. 


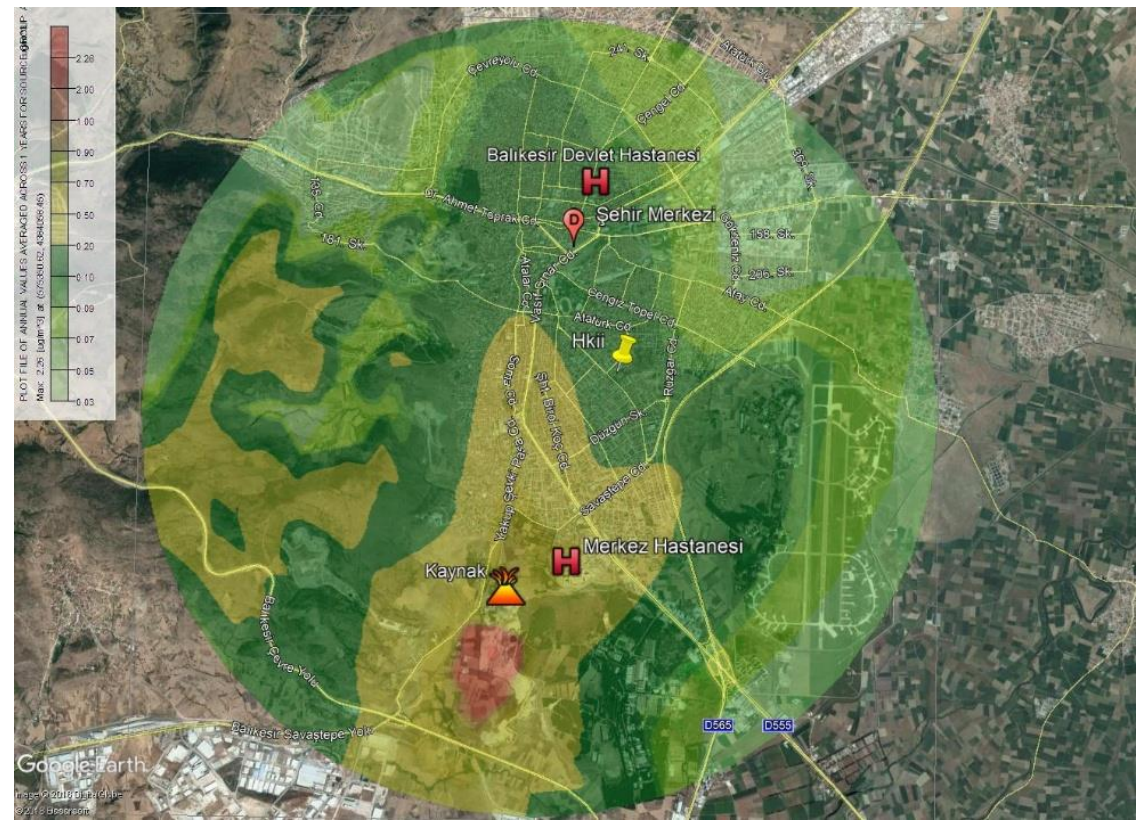

Şekil 5:

Kaynak etkisinde il merkezinde oluşan yıllık CO dağılımı

Son modelleme periyodu olarak, Şekil 5.'de görüleceği üzere yıllık CO konsantrasyonu kaynak etkisindeki dağılım sonucuna göre 2,25 $\mu \mathrm{g} \cdot \mathrm{m}^{-3}$ olarak tahmin edilmiştir. Yıllık dağ $11 \mathrm{~mm}$ mdeline göre, kaynaktan olan CO salınımları daha çok şehir merkezinin güney kısmına doğru yayılım gösterdiği anlaşılmaktadır. Modellenme sonucuna göre, modellenmiş y1llık tahmini CO seviyelerinin ilgili yönetmelikte belirtilen sınır değerinin çok altında kaldığı tespit edilmiştir.

\subsection{Kaynak salınımları: Özel durum}

Çalışmada diğer önemli bir husus ise, Şekil 1.'de görülebileceği üzere, CO salınımı yapan endüstriyel işletmenin yaklaşı $1 \mathrm{~km}$ doğusunda Merkez Hastane kompleksi bulunmaktadır. Dolayısıyla, atmosfere CO salınımı yapan kaynaktan Merkez Hastanesine olası bir etkinin olup olmadığı mutlak suretle incelenmelidir.

$\mathrm{Bu}$ amaçla, AERMOD dağılım modelinde, kaynaktan olan salınımların etkisi altında kalabilecek özel (hassas) yerler tespit edilip, bu gibi yerlerin koordinatları modele işlenerek, bu yerlere kaynaktan olabilecek yeryüzü konsantrasyonları özel olarak tahmin edilebilmektedir.

Merkez Hastanesine, aynı meteorolojik koşullar altında, kaynaktan salınan maksimum günlük 8 saatlik maksimum ortalama yeryüzü CO konsantrasyonu 17.Temmuz.2016, saat 16'da $10,03 \mu \mathrm{g} \cdot \mathrm{m}^{-3}$ olarak tahmin edilmiştir. Söz konusu kaynaktan salınan CO konsantrasyonun, Merkez Hastanesine olası etkisi yasal sınırların altında olup, herhangi bir sağlık riski oluşturmadığ̣ düşünülmektedir.

\subsection{AERMOD tahminlerinin doğrulanması}

Çalışmada kullanılan dağılım modeline ait tahminlerin geçerliliği için ölçülen meteorolojik parametrelerin modelde kullanılan tahmin edilmiş parametreler ile birlikte istatiksel analizlerinin yapılmas1 gerekmektedir (Abril ve ark., 2016) .

Chang ve Hanna (2004) çalışmalarında belirttiği üzere, hava kalitesi modelleme çalışmasında kullanılan en önemli meteorolojik parametrelerden olan rüzgar hızı, residual analizi ile incelenmiş ve sonuçlar Tablo 2'de sunulmuştur. 
Tablo 2. Model doğrulaması için hesaplanan parametreler

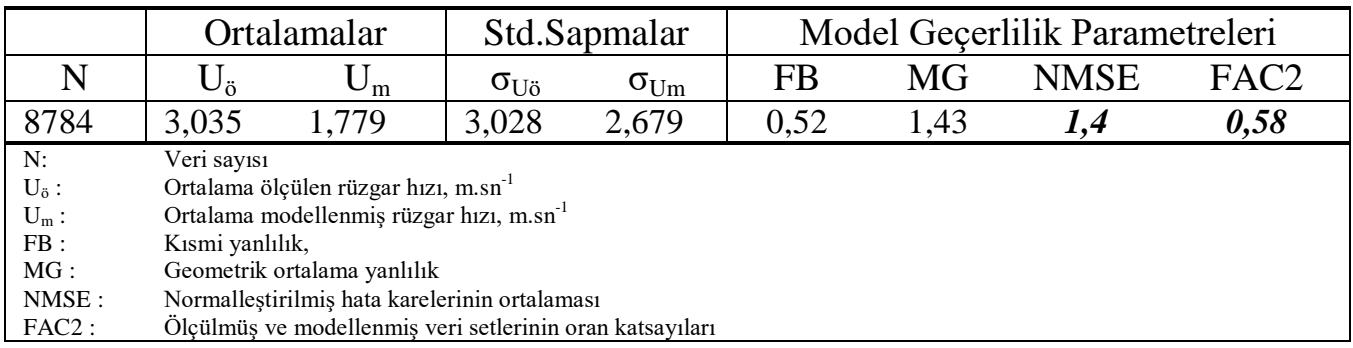

Chang ve Hanna (2004) yapmış oldukları çalışmada, model geçerlilik parametrelerinin hesaplanma yöntemlerini ve bu kontrol parametrelerinin veri setlerinin dağılımlarından gelen belirli aralıklar dahilinde olması gerektiğini ifade etmişlerdir. Bu nedenle sözkonusu kontrol parametrelerine ait kabul aralıkları şu şekilde verilmiştir: FB: $-0,3<\mathrm{FB}<0,3$; MG: $0,7<\mathrm{MG}<$ 1,3; NMSE: $<1,5 ;$ FAC2; $0,5 \leq \frac{U \mathrm{Um}}{\mathrm{Uö}} \leq 2$.

Yine aynı çalışmada, bir modelin geçerliliğin sağlanabilmesi için Tablo 2'de hesaplanan model geçerlilik parametrelerinden en az birinin uygun geçerli aralıklar içinde olması gerektiği ifade edilmiştir. $\mathrm{Bu}$ çalışmada, yapılan analizler sonucunda model geçerlilik parametreleri AERMOD modeli için hesaplanmış ve bu parametrelerden; NMSE $(1,4)$ ve FAC2 $(0,58)$ parametrelerinin uygun geçerli aralıklarda olduğu ve dolayısıyla modelleme çalışmasında kullanılan AERMOD modeline ait sonuçlarının geçerli olduğu sonucuna varılmıştır.

\section{TARTIŞMA ve ÖNERILER}

Balıkesir il merkezinde hava kalitesinin kapsamlı olarak incelenmesi konusunda ilimize ait ilk kez uygulanan ve halen alt yapı çalışmaları devam eden "Temiz Hava Eylem Planı" raporuna katkıda bulunacağı düşüncesiyle ilk adım olarak yapılan bu çalışma hakkında düşünceler aşağıda sunulmuştur:

- Hava kalitesi modelleme çalışmasında kullanılan kaynak (Şekil 1.), şehir merkezinin güneybatısında olduğundan, kaynak etkisi düşünüldüğünde, şehir merkezi yerleşim konumu, kaynaktan çıkan CO salınımların arka planında kaldığı ve dolayısıyla kaynaktan salınan CO emisyonlarının meteorolojik koşullar etkisiyle şehir merkezine doğru olmayıp, şehir merkezinin batı yönünde yayılım yaptığı anlaşılmıştır (Şekil 4.).

- Uzun yıllık ortalamalar dikkate alındığında, Balıkesir ili için hakim rüzgar yönü Şekil 2.'de belirtildiği gibi Kuzey (N) ve Kuzey-Doğu (NE) yönlü rüzgarlar olarak belirlenmiştir.

- Dağılım modeli sonuçlarına göre, tahmin edilen CO konsantrasyonunun yasal sınırları aşmadığı ve şehir merkezine olumsuz bir etkisin olmadığı belirlenmiştir . Bu durum, geçmişe dönük uzun yıllık meteorolojik veriler, özellikle rüzgar yönü, esme sayısı ve özellikle hakim rüzgar yönü dikkate alındığında şehir merkezinde ikamet eden halk açısından olumsuz bir risk teşkil etmediği düşünülmektedir.

- Ayrıca incelenen kaynağa yakın kabul edilebilecek yerde tam teşekküllü bir sağlık merkezinin olması, yapılan çalışmayı daha önemli bir hale getirmektedir. Kirletici dağılım modeline göre, kaynaktan salınan maksimum günlük 8 saatlik ortalama $\mathrm{CO}$ konsantrasyonu yaklaşık $10 \mu \mathrm{g} \cdot \mathrm{m}^{-3}$ olarak tahmin edilmiş olup, bu değerin yönetmelikte izin verilen yasal sınırları aşmadığı tespit edilmiştir.

- Arz edilen çalışma ile birlikte ülkemizde kullanımı hızla artan AERMOD hava kirleticilerinin atmosferik dağılımlarını modelleyen program, bu çalışma kapsamında, Balıkesir il merkezi örneği ile ilimizde ilk kez uygulanmıştır. İlin hava kalitesi değişimlerine yönelik analizde, şehre ait karakteristik kaynak/yüzey/meteorolojik veriler 
kullanılmıştır. Modelleme çalışmasında şu an için sadece tek kaynak verileri kullanılmış olup, sonraki çalışmalarda kaynak sayılarının ve türlerinin de arttırılması gerekmektedir.

- Bundan sonraki ileriye dönük yapılması gereken çalışmalarımız; Balıkesir İli şehir merkezine CO salınımları için direk etkileyebilecek herhangi bir sanayi kaynağı (Noktasal veya alansal) mevcut olmadığından, özellikle şehir merkezi yerleşim alanına ait ulaşım NOx, $\mathrm{PM}_{10}$ ve 1sinmadan kaynaklı $\mathrm{SO}_{2}, \mathrm{PM}_{10}$ ve $\mathrm{CO}$ gibi hava kirleticilerine ait hava kirliliği dağılım haritalarının da oluşturulması ilerisi için önem arz etmektedir.

\section{TEŞEKKÜR}

$\mathrm{Bu}$ çalışmanın gerçekleşmesinde desteklerini esirgemeyen ve her türlü çalışma imkânı sağlayan başta Balıkesir Üniversitesi Rektörlüğü olmak üzere, Balıkesir İl Çevre Müdürlüğü, Balıkesir İl Meteoroloji Müdürlüğü makamlarına teşekkürlerimizi arz ederiz.

\section{KAYNAKLAR}

1. Abril, G.A., Diez, S.C., Pignata, M.L. ve Britch, J. (2016) Particulate matter concentrations originating from industrial and urban sources: Validation of atmospheric dispersion modeling results, Atmospheric Pollution Research, 7, 180-189. https://doi.org/10.1016/j.apr.2015.08.009

2. Alberini, A. ve Krupnick, A. (1998) Air quality and episodes of acute respiratory illness in Taiwan cities: Evidence from survey data, Journal of Urban Economics, 44(1), 68-92. doi: https://doi.org/10.1006/juec.1997.2057

3. Aneja V.P, Agarwal, A., Roelle P.A., Phillips S.B., Tong, Q., Watkins, N. ve Yablonsky R. (2001) Measurements and analysis of criteria pollutants in New Delhi, India, Environment International, 27, 35-42. https://doi.org/10.1016/S0160-4120(01)00051-4

4. Borge, R., Lumbreras, J., Perez, J., de la Paz, D. Ve Vedrenne, M. (2014) Emission inventories and modeling requirements for the development of air quality plans. Application to Madrid (Spain), Science of the Total Environment, 466, 809-819. doi: https://doi.org/10.1016/j.scitotenv.2013.07.093

5. Brunekreef, B. ve Holgate, S.T. (2002) Air pollution and health, The Lancet, 360(9341), 1233-1242. doi: https://doi.org/10.1016/S0140-6736(02)11274-8

6. Carslaw, D.C. (2015) The openair manual - open-source tools for analysing air pollution data. Manual for version 1.1-4, King's College London.

7. Carslaw, D.C. ve K. Ropkins (2012) Openair - an R package for air quality data analysis, Environmental Modelling \& Software,27-28, pp. 52-61.

8. Chang, J.C. ve Hanna, S.R. (2004) Air quality model performance evaluation, Meteorol. Atmos. Phys., 87: 167-196. doi: https://doi.org/ 10.1007/s00703-003-0070-7

9. Gokhale, S. ve Khare, M. (2005) A hybrid model for predicting carbon monoxide from vehicular exhaust in urban environments, Atmospheric Environment, 39, 4025-4040. doi:10.1016/j.atmosenv.2005.04.010

10. Gomzi, M. (1999) Indoor air and respiratory health in preadolescent children, Atmospheric Environment, 33(24-25),4081-4086. doi: https://doi.org/10.1016/S1352-2310(99)00149-1 
11. Hava Kalitesi İzleme. (2018) Hava Kalitesi İzleme Ağı. Çevre ve Şehircilik Bakanlığı web sayfası. Erişim Tarihi: 25.06.2018. Konu: Balıkesir il merkezine ait CO ölçüm raporu.

12. H.K.D.Y.Y. (2008) http://cygm.csb.gov.tr/yonetmelikler-i-440. Erişim Tarihi: 26.01.2018. Konu: Hava Kalitesi Değerlendirme ve Yönetimi Yönetmeliği.

13. Helander, M. L., Savolainen, J., and Ahlholm, J. (1997) Effects of air pollution and other environmental factors on birch pollen allergens, Allergy: European Journal of Allergy \& Clinical Immunology, 52(12),1207-1214. doi: https://doi.org/10.1111/j.13989995.1997.tb02525.x

14. Liu, C., Yin, P., Chen, R., Meng, X., Wang, L., Niu, L., Lin, Z., Liu, Y., Liu, J., Qi, J., You, J., Kan, H. ve Zhou, M. (2018) Ambient carbon monoxide and cardiovascular mortality: a nationwide time-series analysis in 272 cities in China, The Lancet Planetary Health, 2, e12e18. https://doi.org/10.1016/S2542-5196(17)30181-X

15. Martonen T,B., ve Schroeter, J.D. (2003) Risk assessment dosimetry model for inhaled particulate matter: I. Human subjects, Toxicology Letters, 138(1-2), 119-132. doi: https://doi.org/10.1016/S0378-4274(02)00411-3

16. Monn, C., Alean-Kirkpatrick, P., Künzli, N., Defila, C., Peeters, A., Ackermann-Liebrich, U., Leuenberger, F. and SAPALDIA Team. (1999) Air pollution, climate and pollen comparisons in urban, rural and alpine regions in Switzerland (SAPALDIA study), Atmospheric Environment, 33(15), 2411-2416. doi: https://doi.org/10.1016/S13522310(99)00068-0

17. Moshammer, H ve Neuberger, M. (2003) The active surface of suspended particles as a predictor of lung function and pulmonary symptoms in Austrian school children, Atmospheric Environment, 37, 1737-1744. doi: https://doi.org/10.1016/S13522310(03)00073-6

18. SKHKKY-EK1 (2014) http://cygm.csb.gov.tr/yonetmelikler-i-440. Erişim Tarihi: 26.01.2018. Konu: Sanayi Kaynaklı Hava Kirliliğinin Kontrolü Yönetmeliği Ek-1.

19. Tecer, L.H. (2009) A factor analysis study: Air pollution, meteorology, and hospital admissions for respiratory diseases, Toxicological \& Environmental Chemistry, 91(7): 1399-1411. doi: https://doi.org/10.1080/02772240902732316

20. Timonen, K.L., Pekkanen, J., Tiittanen, P. ve Salonen, R.O. (2002) Effects of air pollution on changes in lung function induced by exercise in children with chronic respiratory sypmtoms, Occup Environ Med, 59.129-134. doi: http://dx.doi.org/10.1136/oem.59.2.129

21. USEPA, (2018) https://www.epa.gov/co-pollution, Erişim Tarihi: 26.01.2018, Konu: Carbon Monoxide (CO) Pollution in Outdoor Air.

22. Vallero, D. A. (2008) Fundementals of Air Pollution, Fourth Edition, Elsevier Academic Press, UK.

23. Visscher, A. (2014) Air Dispersion Modeling, John Wiley \& Sons Press. Hoboken, New Jersey.

24. Wang, L.K., Pereria, N.C., ve Hung, Y.T. (2004) Air Pollution Control Engineering, Humana Press, Totowa, New Jersey.

25. Williams, R., Creason, J., Zweidinger, R., Watts, R., Sheldon L., ve Shy, C. (2000) Indoor, outdoor, and personal exposure monitoring of particulate air pollution: the Baltimore elderly epidemiology-exposure pilot study, Atmospheric Environment,34(24), 4193-4204. doi: https://doi.org/10.1016/S1352-2310(00)00209-0 
Mutlu A.: Sanayi Kaynaklı Karbonmonoksit Salınımlarının AERMOD Dağııım Modeli İle İncelenmesi

26. Wong, G. W. K., Ko, F. W. S., Lau, T. S., Li, S. T., Hui, D., Pang, S. W., Leung, R., Fok, T. F. ve Lai, C. K. W. (2000) Temporal relationship between air pollution and hospital admissions for asthmatic children in Hong Kong, Clinical and Experimental Allergy, 31(4), 565-569. doi: https://doi.org/10.1046/j.1365-2222.2001.01063.x

27. Wordley, J., Walters, S. ve Ayres, J. (1997) Short term variations in hospital admissions and mortality and particulate air pollution, Occupational \& Environmental Medicine, 54(2), 108-116. doi: http://dx.doi.org/10.1136/oem.54.2.108 